\title{
Activation of frontal neocortical areas by vocal production in marmosets
}

\section{Cristiano S. Simões ${ }^{1,2}$, Paulo V. R. Vianney ${ }^{3}$,Marco Marcondes de Moura, ${ }^{4,5}$, Marco A. M. Freire ${ }^{1}$, Luiz E. Mello ${ }^{6}$, Koichi Sameshima7, , John F. Araújo' ${ }^{2}$, Miguel A. L. Nicolelis,7,9,10,11, Claudio V. Mello ${ }^{3}$ and Sidarta Ribeiro ${ }^{1,2 *}$}

\author{
1 Edmond and Lily Safra - International Institute of Neuroscience of Natal, Natal, Rio Grande do Norte, Brazil \\ 2 Department of Physiology, Federal University of Rio Grande do Norte, Natal, Rio Grande do Norte, Brazil \\ ${ }^{3}$ Department of Behavioral Neuroscience, Oregon Health and Science University, Portland, OR, USA \\ ${ }^{4}$ Department of Physiology, University of Brasilia, Brasilia, Distrito Federal, Brazil \\ ${ }^{5}$ Laboratory of Brain Studies, Juquery Hospital, Franco da Rocha, São Paulo, Brazil \\ ${ }^{6}$ Department of Physiology, Federal University of São Paulo, São Paulo, São Paulo, Brazil \\ 7 Cesar Timo-laria Laboratory, Instituto de Ensino e Pesquisa, Hospital Sírio-Libanês, São Paulo, São Paulo, Brazil \\ ${ }^{8}$ Department of Radiology, University of São Paulo, São Paulo, São Paulo, Brazil \\ ${ }_{9}$ Center for Neuroengineering, Department of Neurobiology, Duke University Medical Center, Durham, NC, USA \\ ${ }^{10}$ Department of Biomedical Engineering, Duke University, Durham, NC, USA \\ "Department of Psychological and Brain Sciences, Duke University, Durham, NC, USA
}

\section{Edited by:}

John J. Foxe, Nathan S. Kline Institute for Psychiatric Research, USA

\section{Reviewed by:}

Asif A. Ghazanfar, Princeton University, USA

Gary Donohoe, Trinity College Dublin, Ireland

\section{${ }^{*}$ Correspondence:}

Sidarta Ribeiro,

Edmond and Lily Safra - International Institute of Neuroscience of Natal (ELS-IINN), Rua Professor Francisco Luciano de Oliveira, 2460, Natal, Rio Grande do Norte, 59066-060, Brazil. e-mail: ribeiro@natalneuro.org.br
Primates often rely on vocal communication to mediate social interactions. Although much is known about the acoustic structure of primate vocalizations and the social context in which they are usually uttered, our knowledge about the neocortical control of audio-vocal interactions in primates is still incipient, being mostly derived from lesion studies in squirrel monkeys and macaques. To map the neocortical areas related to vocal control in a New World primate species, the common marmoset, we employed a method previously used with success in other vertebrate species: Analysis of the expression of the immediate early gene Egr- 1 in freely behaving animals. The neocortical distribution of Egr-1 immunoreactive cells in three marmosets that were exposed to the playback of conspecific vocalizations and vocalized spontaneously ( $\mathrm{H} / \mathrm{N}$ group) was compared to data from three other marmosets that also heard the playback but did not vocalize (H/n group). The anterior cingulate cortex, the dorsomedial prefrontal cortex and the ventrolateral prefrontal cortex presented a higher number of Egr-1 immunoreactive cells in the $\mathrm{H} / \mathrm{N}$ group than in $\mathrm{H} / \mathrm{n}$ animals. Our results provide direct evidence that the ventrolateral prefrontal cortex, the region that comprises Broca's area in humans and has been associated with auditory processing of species-specific vocalizations and orofacial control in macaques, is engaged during vocal output in marmosets. Altogether, our results support the notion that the network of neocortical areas related to vocal communication in marmosets is quite similar to that of Old world primates. The vocal production role played by these areas and their importance for the evolution of speech in primates are discussed.

Keywords: vocalization, speech, auditory, neocortex, immediate early gene, Egr-1, broca, primate

\section{INTRODUCTION}

Many primate species rely on vocal communication to mediate social interactions (Epple, 1968; Seyfarth et al., 1980; Boinski, 1993; Boinski et al., 1994; Clark and Wrangham, 1994; Vitale et al., 2003; Arnold and Zuberbühler, 2006), and the complexity of their call repertoires appears to be a function of adaptive pressure (Stephan and Zuberbühler, 2008). In spite of the importance of primate vocal communication, our understanding of its neural underpinnings is still quite limited. Most studies have focused on the auditory processing of species-specific calls (Aitkin et al., 1988; Aitkin and Park, 1993; Rauschecker et al., 1995; Wang et al., 1995; Lu et al., 2001; Bendor and Wang, 2005; Wang et al., 2005; Petkov et al., 2008), whereas relatively little is known about the brain representation of vocal-motor programs.

Early studies based on electrical stimulation (Jürgens et al., 1967; Jürgens and Ploog, 1970) or lesions (Sutton et al., 1974; Aitken, 1981) implicated the anterior cingulate cortex (ACC) with vocal control in macaques and squirrel monkeys. These results were supported by anatomical studies indicating a connection between the ACC and the periaqueductal gray (PAG), a brainstem structure involved with vocal motor output in monkeys (Jürgens and Pratt, 1979a,b; Jürgens and Zwirner, 1996; An et al., 1998) and other vertebrates (Kittelberger et al., 2006; Jürgens, 2009). The ACC was also found to have bidirectional connections with auditory associative areas (Barbas et al., 1999), and to exert a predominantly inhibitory control over extensive secondary auditory regions in the superior temporal gyrus (MüllerPreuss et al., 1980). In contrast, no evidence was initially found for an involvement of neocortical areas such as the left ventrolateral prefrontal cortex (VLPFC), which in humans corresponds to Broca's area for articulated speech (comprising Brodmann's areas 44 and 45). A main conclusion of these experiments was the notion that the ACC may be the sole cortical structure for vocal control in non-human primates, differently from the evolutionary branch that led to the origin of the human vocal pathway. 
However, ethological approaches associated with quantitative histological analysis, high-resolution recordings of neuronal activity, and pharmacological or molecular manipulations of brain activity have improved our understanding of the neocortical system for vocal communication in non-human primates (Ghazanfar and Hauser, 1999). A variety of studies suggest the involvement of areas other than the ACC, especially parts of the prefrontal cortex, in the processing of species-specific auditory stimuli. For example, an auditory domain that includes areas 12 and 45 of the macaque brain has been found to be strongly responsive to species-specific vocalizations (Romanski and Goldman-Rakic, 2002). Functional imaging studies using playbacks of conspecific vocalizations have detected activation of this same region in one out of two monkeys (Petkov et al., 2008), and of the homologues of Broca's and Wernicke's areas in the macaque brain (Gil-da-Costa et al., 2006, but see Ghazanfar and Miller, 2006 for a critique of this work). Diffusion tensor imaging data have suggested an evolutionary gradient regarding the degree of connectivity between Broca's and Wernicke's areas: reduced in macaques, moderate in chimpanzees, and abundant in humans (Rilling et al., 2008). Furthermore, electrical stimulation of an area in macaques that is cytoarchitectonically homologous to area 44 in humans has been shown to elicit orofacial responses (Petrides et al., 2005). Despite these achievements, direct evidence of the involvement of the VLPFC in the control of vocal output in non-human primates is still missing.

The analysis of the expression of immediate early genes (IEGs) has been used to generate high-resolution maps of brain activation in response to specific stimuli in behaving animals (Chaudhuri, 1997). This approach has been particularly successful in the identification of auditory (Mello et al., 1992; Ribeiro et al., 1998) and vocal-motor representations in birds (Jarvis and Nottebohm, 1997; Jarvis and Mello, 2000; Jarvis et al., 2000; Mello, 2002). The avian studies of vocal control have focused on ZENK (a.k.a. zif-268, Egr-1, NGFI-A, and krox-24), an IEG highly sensitive to neuronal depolarization that is involved with synaptic plasticity (Wisden et al., 1990; Nottebohm, 1997; Jones et al., 2001; Mello 2002; Knapska and Kaczmarek, 2004). In saddle-back tamarins, expression of the IEG c-FOS has been found to increase in the ACC, dorsomedial prefrontal cortex (DMPFC), and VLPFC (Jürgens et al., 1996), but the vocalizations in this study were evoked by electrical stimulation of the PAG rather than occurring spontaneously, thus limiting the interpretation of the findings. Preliminary Egr-1 immunolabeling data from marmosets undergoing spontaneous vocal production suggests that frontal neocortical areas are activated in this condition (Simões et al., 2007, 2008). Preliminary c-FOS data in marmosets also suggest the involvement of neocortical areas in antiphonal calling (Miller et al., 2005).

The common marmoset (Callithrix jacchus) stands out as a model organism that may yield further insights into the biology of vocal communication in non-human primates. Marmosets present a relatively simple neocortical architecture, very conspicuous vocal behavior (Epple, 1968; Winter, 1978; Mendes et al., 2009), and a complex social hierarchy (Yamamoto et al., 2009). Marmosets and the related cotton-top tamarins also exhibit robust antiphonal calling (Ghazanfar et al., 2001; Miller and Wang, 2006), i.e. a tendency to vocalize back upon hearing species-specific vocalizations, facilitating the design of naturalistic vocal communication paradigms. The marmoset also offers unique opportunities for comparisons between New and Old World primates. Its auditory pathways have been characterized (Aitkin and Park, 1993) and some important features of the auditory cortex have been described, including its tonotopic organization (Aitkin et al., 1986; Bendor and Wang, 2005), connectivity (Aitkin et al., 1988; de la Mothe et al., 2006), and key parameters of the auditory representation of species-specific vocalizations (Wang et al., 1995; Wang and Kadia, 2001; Nagarajan et al., 2002; Bendor and Wang, 2007). In contrast, knowledge about the vocal control pathways in marmosets remains scarce. Importantly, it is still unclear whether the ACC is the predominant cortical vocal area in marmosets, or whether the involvement of prefrontal areas in vocal behavior, at least during auditory processing, can also be extended to this New World species.

Here we describe the neocortical distribution of Egr-1 immunoreactivity in marmosets spontaneously engaged in vocal production. We took advantage of individual differences in the tendency to respond to playbacks of conspecific calls and compared animals that did or did not vocalize during the auditory stimulation. Four areas were analyzed: The auditory cortex (AC), the ACC, the DMPFC, and the VLPFC. We hypothesized that the three frontal areas would present a greater number of Egr-1 reactive cells per unit area in the vocalizing animals than in the hearing only ones, while no significant differences would be found among them in the AC, showing that frontal neocortical areas, such as the DMPFC and the VLPFC are activated during vocal production in non-human primates.

\section{MATERIALS AND METHODS ANIMALS}

All animal work including housing, surgical, and recording procedures were in strict accordance with the National Institutes of Health guidelines, and was approved by the Edmond and Lily Safra International Institute of Neuroscience of Natal Committee for Ethics in Animal Experimentation. Seven adult male common marmosets (C. jacchus) reared in captivity were initially housed individually for $24 \mathrm{~h}$ in sound-attenuating chambers (sound attenuation of $\sim 50 \mathrm{~dB}$, $40 \times 40 \times 50 \mathrm{~cm}$, dimensions in accordance with (Council, 1996).

\section{BEHAVIORAL PARADIGM}

After the 24-h isolation period, six animals were stimulated for $45 \mathrm{~min}$ (Figure 1A) with a playback of conspecific vocalizations. The playback tape was obtained by continuously recording freely uttered vocalizations of adult captive marmosets unfamiliar to the animals investigated here (sampling rate $44 \mathrm{kHz}$, duration of $45 \mathrm{~min})$. The vocalizations present in the playback were phee calls ( 4.92 calls $/ \mathrm{min})$, twitter calls ( 1.75 calls $/ \mathrm{min})$, and chatter calls (0.38 calls/min) (Figure 1B). The tape was not edited and was presented non-stop to the experimental animals at $70 \mathrm{~dB}$ at $1 \mathrm{~m}$ through a high fidelity speaker (Selenium Super Tweeter ST350, frequency response: $2.500-20.000 \mathrm{~Hz}$ ) positioned inside the chamber but kept out of the animals' reach by an acrylic screen. The "hearing and vocalizing" group $(\mathrm{H} / \mathrm{V}, n=3)$ consisted of animals that spontaneously vocalized upon hearing the playback (phee calls, number of calls ranging from 41 to 75; one animal also uttered 19 chatter calls). In contrast, the "hearing only" group $(\mathrm{H} / \mathrm{n}, n=3)$ consisted of animals that did not vocalize at all during presentation of the stimulus. 


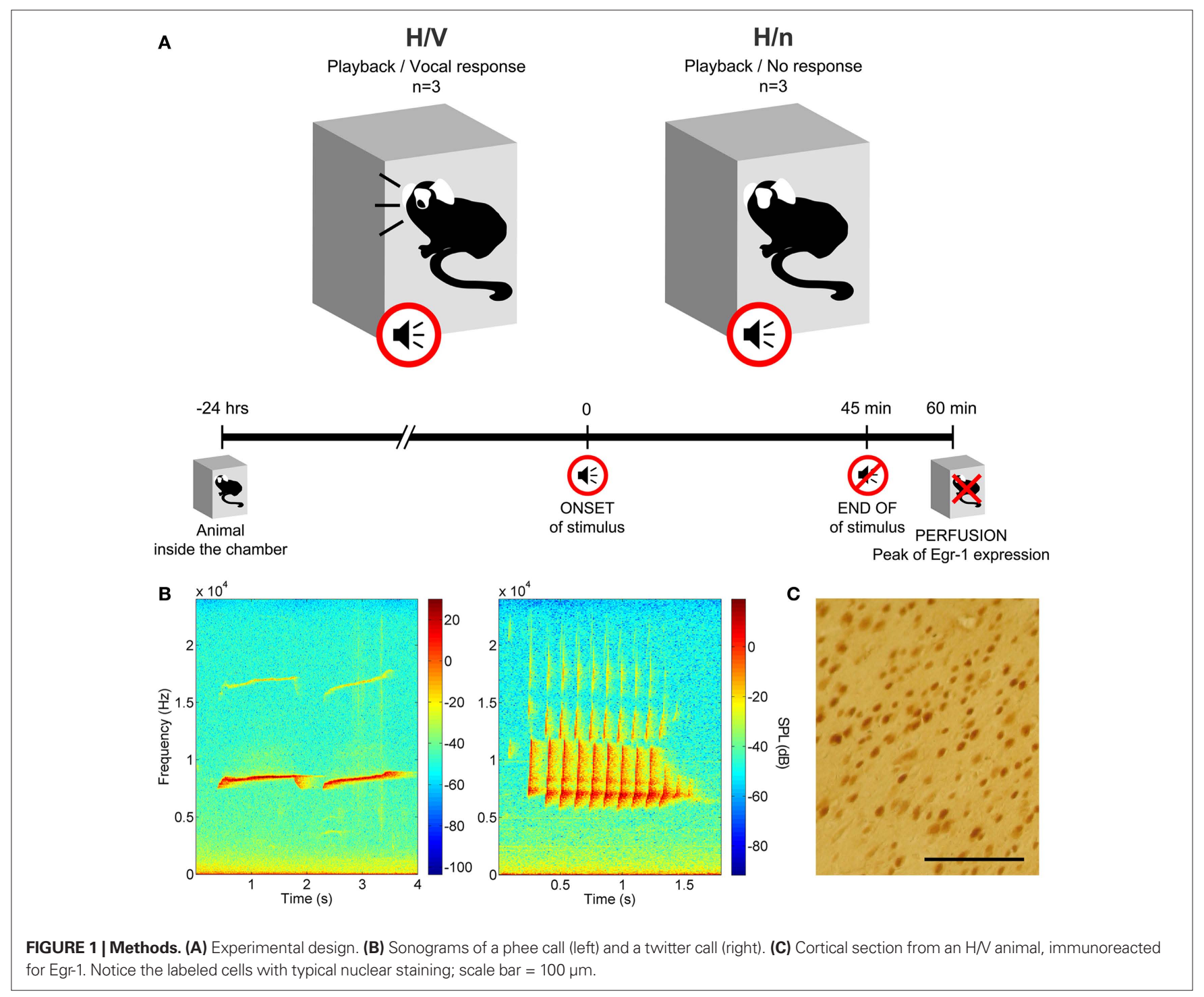

\section{TISSUE PREPARATION}

The animals were killed $60 \mathrm{~min}$ after the onset of stimulation so as to match the peak of Egr-1 protein expression (Knapska and Kaczmarek, 2004). The sound-attenuated chambers were filled with $5 \%$ isofluorane in oxygen (Cristália, Brazil), and after 5 min animals received an overdose of sodium thiopental (Cristália, Brazil; $50 \mathrm{mg} /$ $\mathrm{kg}$, intraperitoneal injection). Animals were then intracardially perfused with heparinized phosphate-buffered saline (PBS) at $37^{\circ} \mathrm{C}$, followed by $4 \%$ paraformaldehyde in $0.1 \mathrm{M}$ phosphate buffer (PB), $\mathrm{pH} 7.4$, at $4^{\circ} \mathrm{C}$. The brains were removed, washed for $24 \mathrm{~h}$ in $0.1 \mathrm{M}$ $\mathrm{PB}, \mathrm{pH} 7.4$, at $4{ }^{\circ} \mathrm{C}$, and cryoprotected for another $24 \mathrm{~h}$ in $20 \%$ sucrose in $0.1 \mathrm{M} \mathrm{PB}$ at $4^{\circ} \mathrm{C}$. The brains were then rapidly frozen in embedding medium (Tissue-Tek, Japan) using a mix of dry ice and ethanol, stored at $-80^{\circ} \mathrm{C}$, sectioned coronally at $20 \mu \mathrm{m}$ on a cryostat (Micron HM 550, Germany), and thaw-mounted on glass slides (SuperFrost Plus, VWR International, USA). To facilitate the identification of areas of interest, serial sections (one at every $200 \mu \mathrm{m}$ ) from all brains were stained for Nissl $(0.1 \%$ cresyl violet $)$.

\section{IMMUNOHISTOCHEMISTRY}

Selected sections corresponding to the cortical areas of interest (see definition below) were processed for immunohistochemistry for the Egr-1 protein according to a standard protocol (Mello and Ribeiro, 1998; Ribeiro et al., 1998). Briefly, the sections were: (1) washed for $30 \mathrm{~min}$ in $0.1 \mathrm{M} \mathrm{PB}$; (2) incubated for $30 \mathrm{~min}$ in a blocking buffer (BB) solution $(0.5 \%$ fresh skim milk and $0.3 \%$ Triton $\mathrm{X}-100$ in $0.1 \mathrm{M} \mathrm{PB}$ ); (3) incubated overnight in rabbit primary antibody (1:100 dilution in BB; SC-189; Santa Cruz Biotechnology, USA); (4) washed for $30 \mathrm{~min}$ in $0.1 \mathrm{M} \mathrm{PB}$; (5) incubated for $2 \mathrm{~h}$ in biotinylated goat anti-rabbit secondary antibody (1:200 dilution in BB; BA-1000; Vector Labs, USA); (6) washed for $30 \mathrm{~min}$ in $0.1 \mathrm{M} \mathrm{PB}$; 7) incubated in an avidin-biotin-peroxidase complex (PK-4000; Vectastain Standard ABC kit; Vector Labs, USA) for $2 \mathrm{~h}$; and (8) placed in a solution containing $0.03 \% 3,3$ diaminobenzidine (DAB; D5637; Sigma, USA) and 0.001\% hydrogen peroxide in $0.1 \mathrm{M} \mathrm{PB}$. Reaction was stopped after a few minutes by rinsing the sections in $0.1 \mathrm{M} \mathrm{PB}, \mathrm{pH}$. 7.4. Sections were then dehydrated 
through a series of graded alcohols and coverslipped with Entellan (Merck, Germany). In order to verify the specificity of the labeling, the primary antibody was replaced by blocking buffer in some test sections. Considering that a large number of brain sections were analyzed per animal, the overall number of sections for the entire study was too large to be processed in a single immunohistochemistry batch. Therefore we reacted and quantified the sections in three smaller batches, each including sections from one animal in the $\mathrm{H} / \mathrm{V}$ group paired with comparable sections from one animal in the $\mathrm{H} / \mathrm{n}$ group.

\section{DEFINITION OF CORTICAL AREAS OF INTEREST}

The coronal sections containing areas of interest were identified by consulting the brain atlas of the common marmoset (Stephan et al., 1980). The AC was sampled in sections at A+5.5 (Figure 2A). This specific portion of the $\mathrm{AC}$ was chosen because of its involvement in the processing of frequencies around $8 \mathrm{kHz}$ (Aitkin et al., 1988), which are characteristic of phee calls, the prevailing call type in our stimulus tape. The other three cortical areas of interest were sampled in more anterior sections at A+13.8 mm (Burman et al., 2006), which includes the most anterior portion of the ACC, next to the genu (Paus, 2001), area $6 \mathrm{~m}$ of the DMPFC (Jürgens et al., 1996; Burman et al., 2006), and the transitional region of area 12/45, which most resembles area 45 in macaques (Burman et al., 2006) (Figures 2D,G,J).

\section{CELL COUNTING AND STATISTICAL ANALYSIS}

For each cortical area examined, three adjacent coronal sections from each animal were chosen for quantitative analyses. In each section, Neurolucida software (MicroBrightField, Inc., USA) was used to delimit regions of interest (ROIs), defined as $200-\mu \mathrm{m}$ wide square boxes drawn sequentially over the cerebral cortex of both hemispheres so as to sample the tissue at regular intervals from the outer cortical layers to the white matter (Figures $\mathbf{2 B}, \mathbf{E}, \mathbf{H}, \mathbf{K}$ ). In each area, the first ROI was positioned on the border between layers I and II, as defined by inspection of adjacent sections stained with cresyl violet. The subsequent ROIs were oriented perpendicularly to the cortical surface line and equally spaced by 100 $\mu \mathrm{m}$ intervals, in a total of 4-6 non-overlapping boxes, depending on the cortical depth of each area (Figures 2C,F,I,L). All cells within ROIs identified as immunolabeled for Egr-1 were counted at the $40 \times$ magnification. Labeled cells could be unambiguously identified due to a characteristic nuclear pattern of staining (Figure 1C). We did not rank the cells with respect to the intensity of immunolabeling. In order to perform group comparisons with the resulting cell counts, we combined the data from the three separately reacted batches. For this purpose, we first used a normalization procedure which consisted in dividing the number of labeled cells within each ROI by the total number of labeled cells in the corresponding batch of reacted sections. For a general group comparison, we then plotted the normalized labeled cell
A
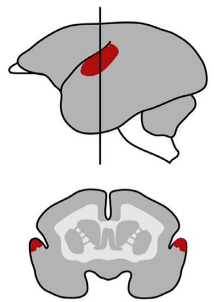

E
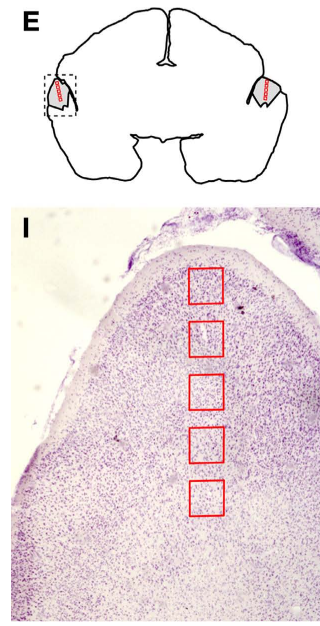

B
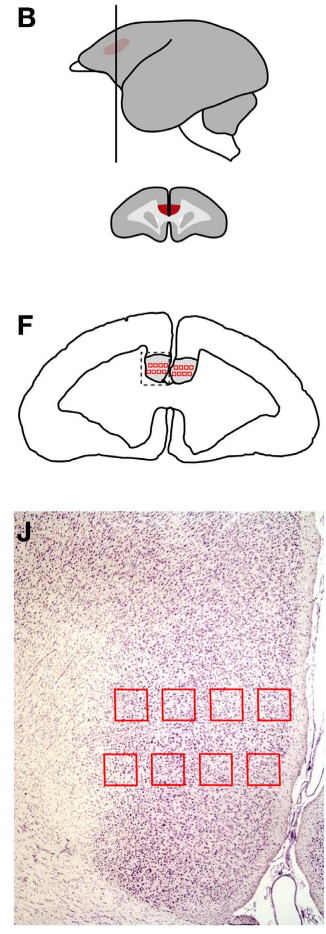

FIGURE 2 | Neuroanatomical location of the cortical areas investigated and positioning of the regions of interest (ROls) according to cortical depth. (A-C) auditory cortex. (D-F) anterior cingulate cortex. (G-I) dorsomedial prefrontal cortex. (J-L) ventrolateral prefrontal cortex. (A, D, G, and $\mathbf{J}$ ) Lateral view of the brain (left) showing the location of each area (red) and the level at which the brain was sectioned coronally for histological analysis (vertical line; $A+5.5 \mathrm{~mm}$ for $\mathrm{AC} ; \mathrm{A}+13.8 \mathrm{~mm}$ for ACC, DMPFC, and

C
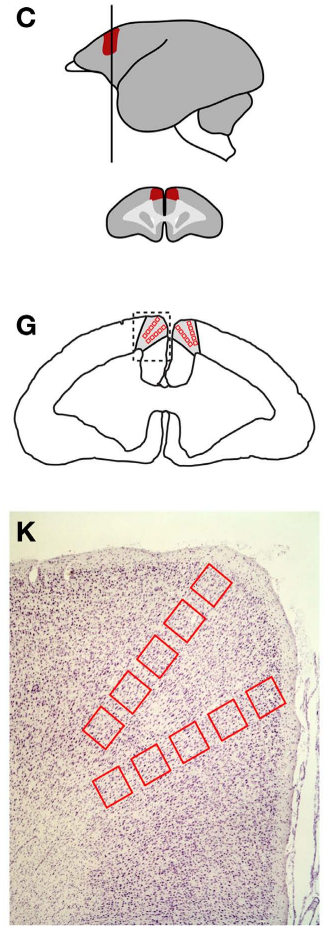

D
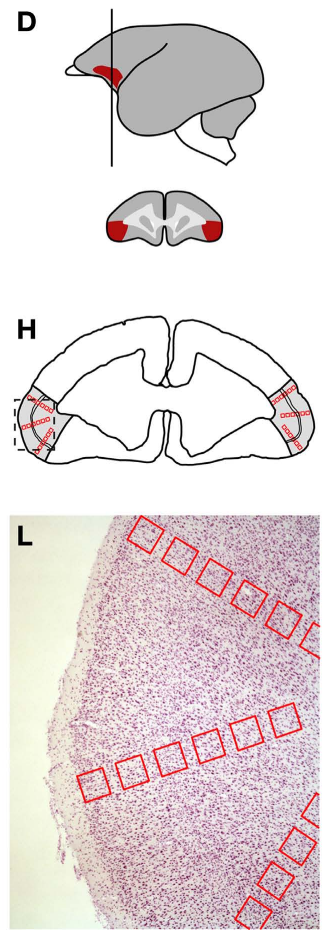

VLPFC). The schematic sections (right) depict the coronal view of each area (B, E, $\mathbf{H}$, and $\mathbf{K}$ ) Outline of a coronal section at the same coordinate as in A, D, G, and $\mathbf{J}$ respectively, showing the placement of the ROIs (red boxes). (C, F, I, and $\mathbf{L}$ ) Nissl-stained samples of brain sections corresponding to the dashed box in $\mathbf{B}, \mathbf{E}, \mathbf{H}$, and $\mathbf{K}$. The ROIs were positioned perpendicularly with respect to the pial surface, so as to assess Egr-1 levels at different cortical depths. 
counts for all ROIs from the three animals in each group in box plots (Figure 4). Due to the low n, we did not subject the data to intergroup statistical analysis.

The sequential positioning of the ROIs made it possible to assess the distribution of labeled cells across different cortical depths within each area analyzed. Thus, for a more detailed regional analysis, we calculated the ratio of the normalized labeled cell counts for each ROI between the $\mathrm{H} / \mathrm{V}$ animal and its $\mathrm{H} / \mathrm{n}$ counterpart, within each of the three separately reacted batches. The values obtained for each ROI from the pairs of matched animals were then averaged across the three separately reacted batches, converted into a pseudocolor scale, and displayed over anatomical drawings of the brain areas analyzed (B graphs in Figures 5-8).

For a more quantitative evaluation of regional/laminar differences in labeling, we plotted the raw cell counts per ROI for individual animals in each group, keeping track of the position of the ROI relative to cortical depth (Graphs A in Figures 5-8). Values across cortical layers were compared using non-parametric statistics (Kruskal-Wallis test followed by Mann-Whitney tests with Bonferroni correction for multiple comparisons) implemented with MATLAB (The MathWorks, Inc., USA). For each cortical region analyzed we also plotted and compared the raw cell count values from all ROIs in the left and right hemispheres (Mann-Whitney test, C graphs in Figures 5-8).

\section{RESULTS}

Overall, the number of Egr-1 immunoreactive cells in the ACC, DMPFC and VLPFC was higher in the H/V group than in the $H / n$ animals (Figures 3 and 4). On the other hand, no major difference was found between the groups in the AC. Detailed results for each cortical area are presented below.

\section{AUDITORY CORTEX}

We observed statistically significant differences in the number of labeled cells across layers within the H/V animals, but the pattern was not consistent across animals, since the differences were detected at different cortical depths in different animals (Figure 5A). The highest ratios between the normalized counts of $\mathrm{H} / \mathrm{V}$ and $\mathrm{H} / \mathrm{n}$ groups were found at ROIs positioned between 300 and $800 \mu \mathrm{m}$ in the left hemisphere and between 0 and $200 \mu \mathrm{m}$ in the right hemisphere (Figure 5B), which could suggest a differential recruitment of layer IV in the left hemisphere and layer II in the right hemisphere when animals vocalize. Notwithstanding, no statistically significant differences were observed between hemispheres in H/V animals (Figure 5C).

\section{ANTERIOR CINGULATE CORTEX}

Within the H/V animals, we observed a non-significant trend for increased labeling in the ROIs between 600 and $800 \mu \mathrm{m}$ in all three animals (Figure 6A). Interestingly, a trend for increased labeling was found in the ROIs between 300 and $500 \mu \mathrm{m}$ in two of the $\mathrm{H} / \mathrm{n}$ animals (data not shown), suggesting a differential recruitment of the supragranular layers of the ACC when animals vocalize. The highest ratios between $\mathrm{H} / \mathrm{V}$ and $\mathrm{H} / \mathrm{n}$ animals in the ACC occurred in the most medial ROIs of the right hemisphere (Figure 6B). Two animals showed statistically significant laterality, in favor of the left hemisphere (Figure 6C, left > right in batches 2 and 3).
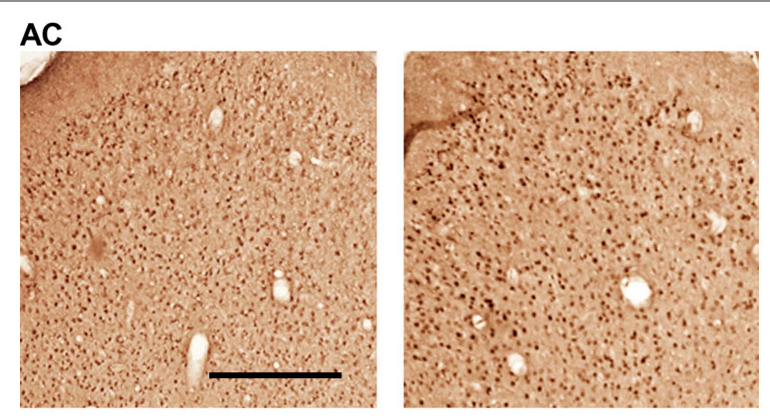

ACC
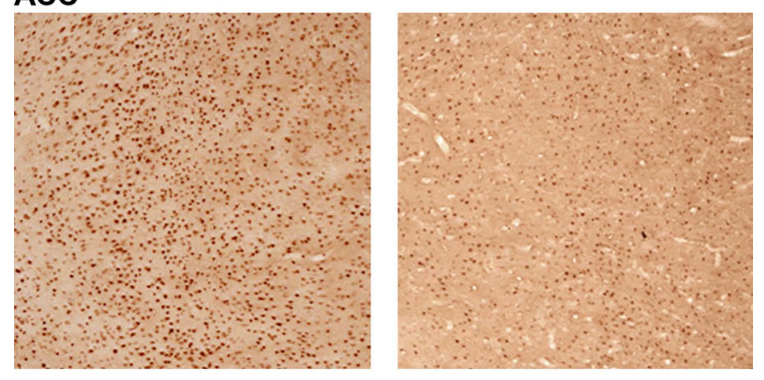

DMPFC
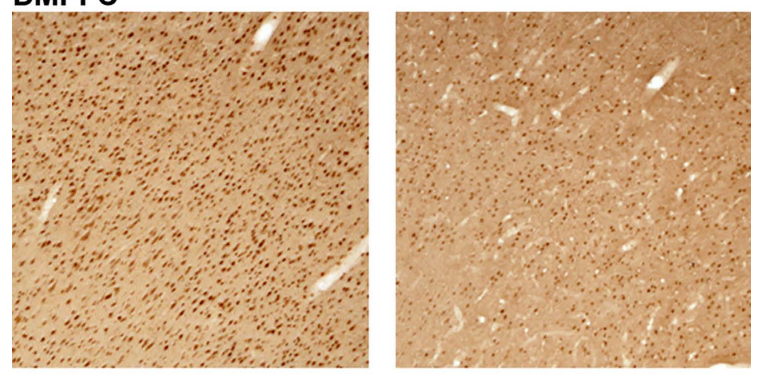

VLPFC
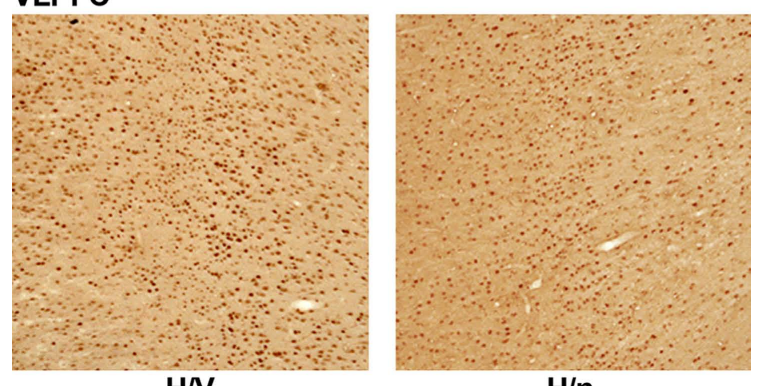

$\mathrm{H} / \mathrm{V}$

$H / n$

FIGURE 3 | Representative samples of each cortical area investigated. Brain sections of one $\mathrm{H} / \mathrm{N}$ and one $\mathrm{H} / \mathrm{n}$ animal were immunoreacted in the same batch for the Egr-1 protein. Scale bar $=500 \mu \mathrm{m}$.

\section{DORSOMEDIAL PREFRONTAL CORTEX}

The depth distribution of Egr-1 labeled cells in two H/V animals revealed a trend for increased labeling between 300 and $800 \mu \mathrm{m}$, but we observed the opposite in the remaining animal (Figure 7A). The highest ratios between $\mathrm{H} / \mathrm{V}$ and $\mathrm{H} / \mathrm{n}$ groups were found in the most superficial ROIs, especially in the right hemisphere (Figure 7B). Only one animal of the H/V group showed a statistically significant difference between hemispheres, with more labeling in the left one (Figure 7C; left > right in batch 3 ). 

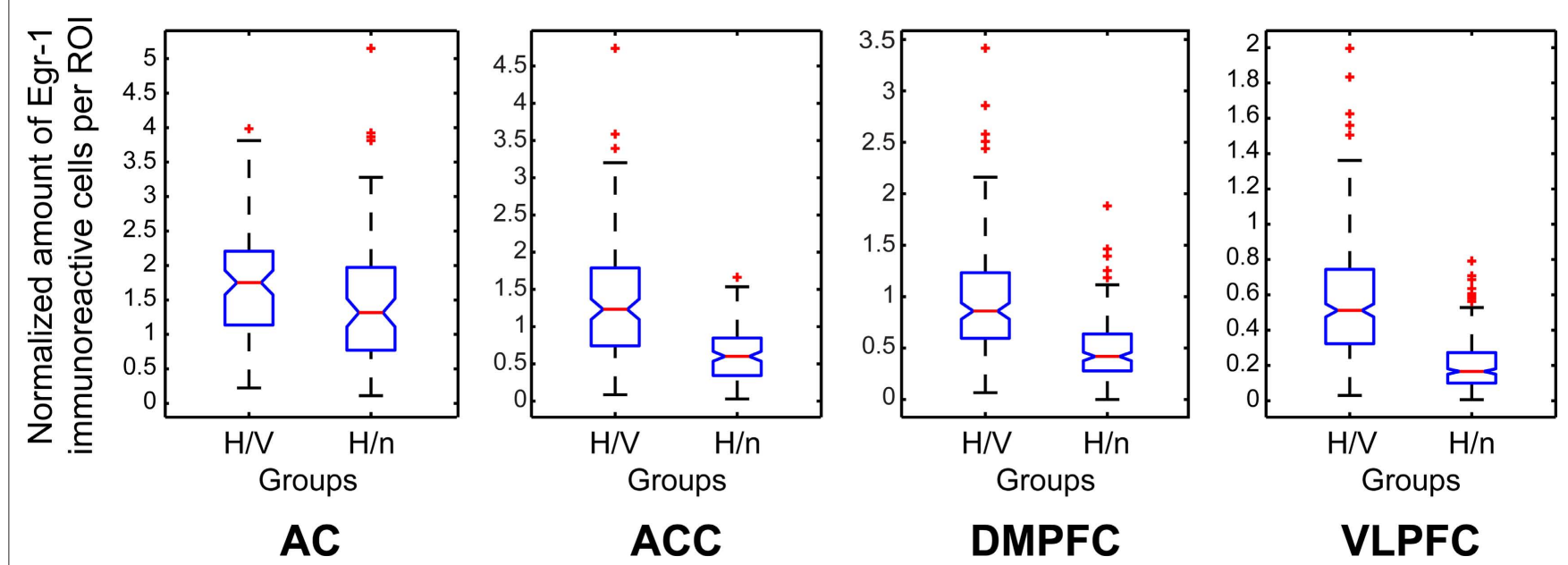

FIGURE 4 | Box plots of the counts of immunoreactive cells per ROI, comprising all ROls of all animals in each group, normalized by the total number of labeled cells per immunoreaction batch, and separated by group for each cortical area investigated.

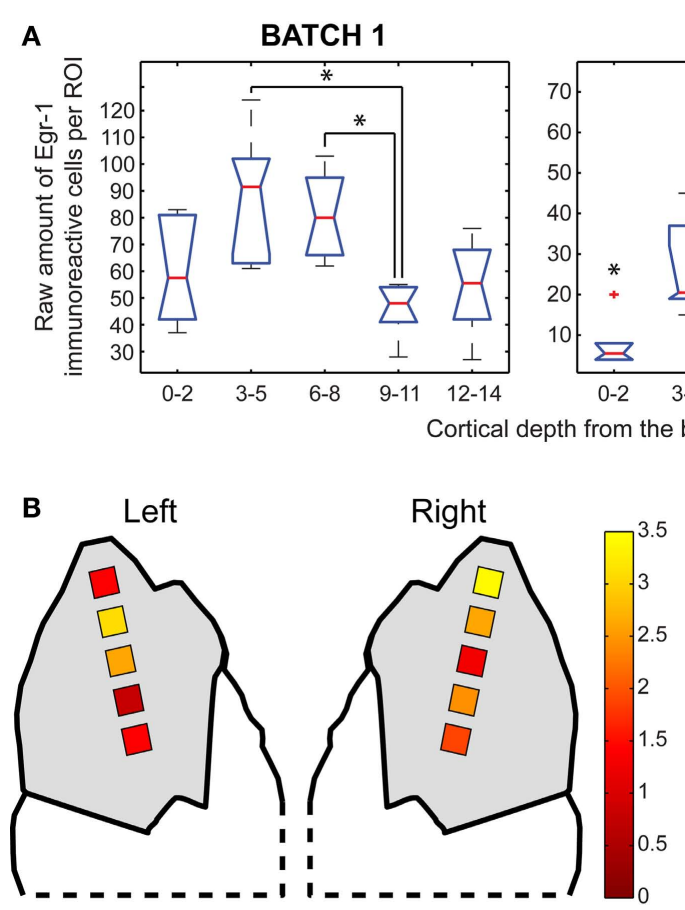

FIGURE 5 | Egr-1 expression in the AC. (A) Box plots of the raw counts of immunoreactive cells per ROI as a function of cortical depth in the HN animals, * indicates significant differences $(p<0.05$, Mann-Whitney tests with Bonferroni
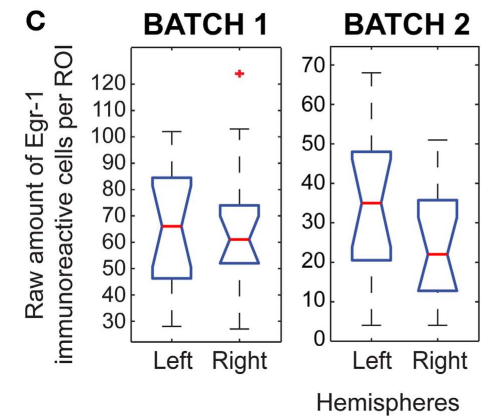

\section{VENTROLATERAL PREFRONTAL CORTEX}

The pattern of cortical depth distribution in the H/V animals showed a consistent trend of increased labeling in the ROIs positioned between 600 and $800 \mu \mathrm{m}$ (Figure 8A). These ROIs were positioned over cortical layer IV and its borders (Figure 2D), as defined by cresyl-violet staining of brain sections adjacent to those. The same pattern was also found in the $\mathrm{H} / \mathrm{n}$ animals, but with lower absolute number of immunoreactive cells (data not shown). This suggests that the VLPFC is more active as
BATCH 2

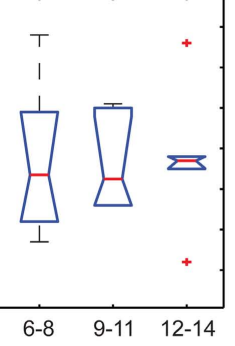

BATCH 3

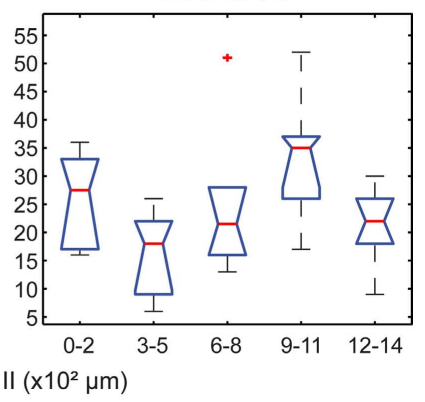

BATCH 3 correction) (B) Maps of average $(\mathrm{H} / \mathrm{N}) /(\mathrm{H} / \mathrm{n})$ ratios of normalized values of immunoreactive cells. (C) Box plots of the raw counts of immunoreactive cells per ROI in each hemisphere of $\mathrm{H} N$ animals (Mann-Whitney test). a whole when animals vocalize. However, the pseudocolored map (Figure 8B) shows that the outer ROIs between 0 and $500 \mu \mathrm{m}$ exhibit the highest Egr-1 labeling ratios between H/V and $\mathrm{H} / \mathrm{n}$ animals. Altogether, these data mean that, although the increase of immunoreactive cells provoked exclusively by vocal output is widespread through the VLPFC, layers II and III are more recruited by vocal behavior than the other layers. Laterality was observed in two animals, but for different hemispheres (Figure 8C). 

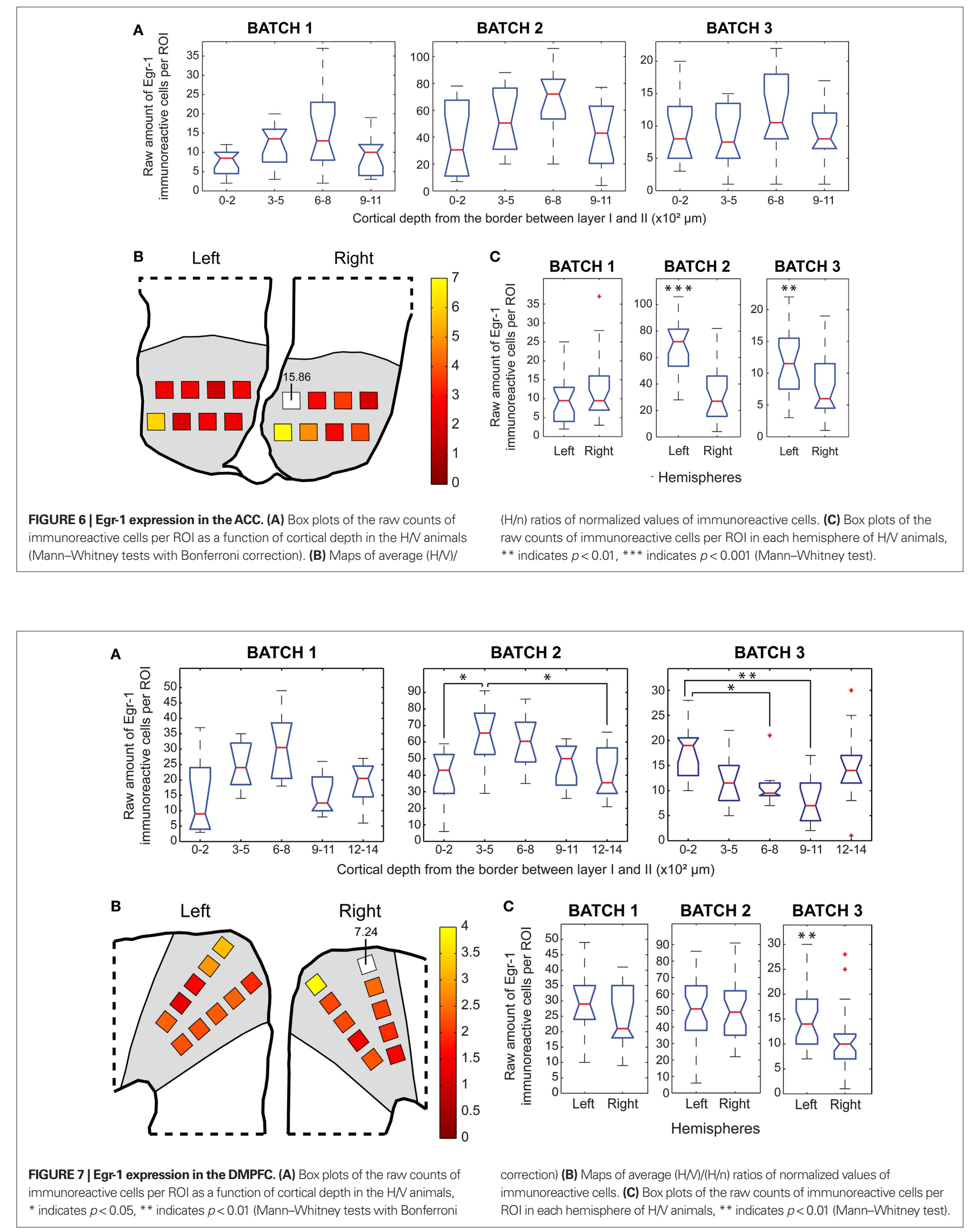
A

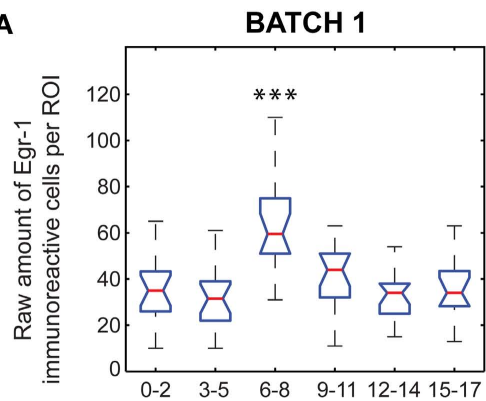

BATCH 2

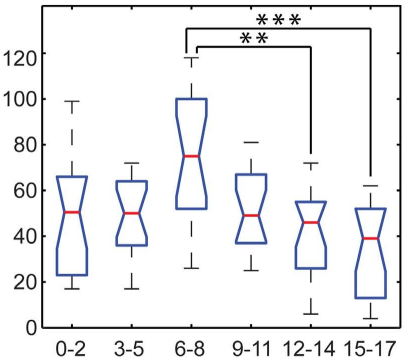

Cortical depth from the border between layer I and II $\left(x 10^{2} \mu \mathrm{m}\right)$

\section{BATCH 3}

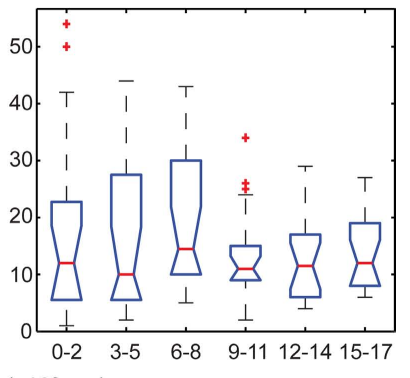

B
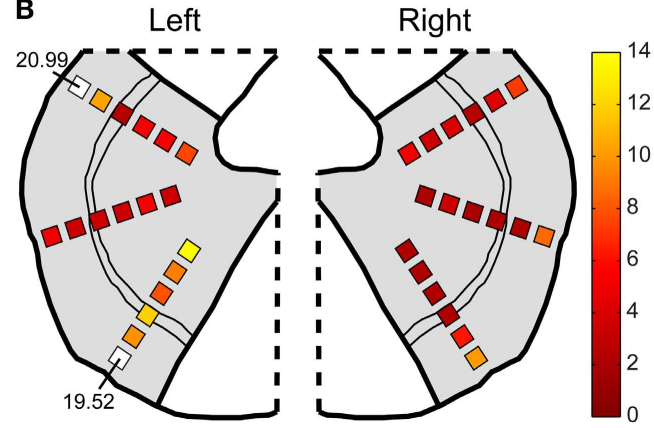

C

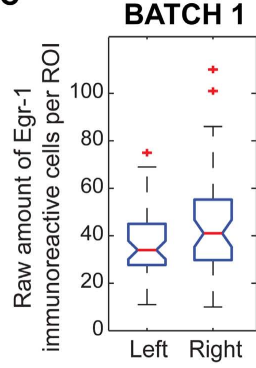

BATCH 2

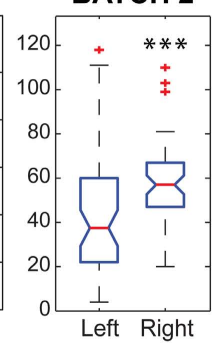

Hemispheres

BATCH 3

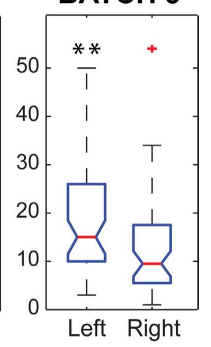

Left Right
FIGURE 8 | Egr-1 expression in the VLPFC. (A) Box plots of the raw counts of immunoreactive cells per $\mathrm{ROI}$ as a function of cortical depth in the $\mathrm{H} / \mathrm{N}$ animals, ${ }^{*}$ indicates $p<0.05,{ }^{*}$ indicates $p<0.01,{ }^{* * *}$ indicates $p<0.001$ (Mann-Whitney tests with Bonferroni correction). (B) Maps of average
$(H / N)(H / n)$ ratios of normalized values of immunoreactive cells. (C) Box plots of the raw counts of immunoreactive cells per $\mathrm{ROI}$ in each hemisphere of $\mathrm{H} / \mathrm{V}$ animals, ${ }^{* *}$ indicates $p<0.01,{ }^{* * *}$ indicates $p<0.001$ (Mann-Whitney test).

\section{DISCUSSION}

Our results show that Egr-1 expression, measured as the number of nuclei immunopositive for the Egr-1 protein per unit area, is strongly induced in the ACC, DMPFC, and VLPFC when animals vocalize upon hearing conspecific calls (H/V group), but not when they hear these calls without vocalizing ( $\mathrm{H} / \mathrm{n}$ group). In contrast, the AC showed increased Egr-1 protein expression in both $\mathrm{H} / \mathrm{n}$ and $\mathrm{H} / \mathrm{V}$ animals. None of the areas analyzed showed a consistent pattern of lateralization, and therefore no conclusion regarding this issue could be drawn from the data.

The equivalent levels of Egr-1 labeling observed in the AC for the $\mathrm{H} / \mathrm{V}$ and $\mathrm{H} / \mathrm{n}$ groups were expected, because the AC corresponds to the primary auditory cortex (Aitkin et al., 1988) and both groups of animals were similarly exposed to playbacks of conspecific calls. Higher Egr-1 labeling in the H/V group than in the $\mathrm{H} / \mathrm{n}$ animals, which occurred in the more anterior areas investigated (ACC, DMPFC, and VLPFC), also matched the expectation that these areas are required for vocal control in marmosets (Jürgens et al., 1996). Altogether, the data provide direct evidence that the prefrontal areas mentioned above are engaged in vocal communication not only by auditory processing but also - and most importantly - by vocal output. In particular, these results are consistent with the ACC playing a role in the neural control of vocalizations in primates. The data also provide direct evidence of the involvement of the DMPFC and especially the VLPFC in the control of vocal output in a non-human primate species. The functional contribution of each of these areas to marmoset vocal communication remains to be determined.
Earlylesion studies (Sutton et al., 1974; Aitken, 1981) were designed to test the hypothesis that non-human primates exert volitional-and not only emotional - control over their vocal output. Those studies were based on discriminative vocal conditioning tasks, not on audiovocal interactions relevant to social context. Therefore, repetitive conditioning may have biased the results. It is currently accepted that distinct subdivisions of the ACC are differentially involved in a variety of cognitive and motor functions, but mostly as an interface among cognition, emotion, volition, and motor output (Paus, 2001). The functional contribution of the ACC to vocal control is probably restricted to the voluntary initiation of vocal utterances (MüllerPreuss et al., 1980; Paus, 2001). Evidence from squirrel monkeys indicates that inactivation of the PAG blocks vocalizations elicited by stimulation of the cingulate cortex (Düsterhöft et al., 2000). That study revealed that some ACC neurons were particularly active during the short amount of time elapsed between hearing the vocalizations of another individual and uttering an antiphonal response (Düsterhöft et al., 2000). A similar study revealed that PAG inactivation blocks vocalizations elicited by electrical stimulation of forebrain sites such as the cingulate cortex and the hypothalamus, but does not affect vocalizations elicited by stimulation of the caudal midbrain, pons or medulla (Siebert and Jürgens, 2003), where neuronal firing has been found to be correlated with different spectral features of the vocalizations (Lüthe et al., 2000). Taken together, these findings suggest that the ACC works as a volitional gate for vocal production.

In humans, focal bilateral lesions of the ACC are associated with akinetic mutism, characterized by a marked impairment in the spontaneous initiation of speech (Paus, 2001). Patients with 
unilateral lesions of the ACC display aprosodic and monotonous speech, characterized by hesitation (Paus, 2001). These observations support an involvement of the ACC in the volitional control of emotional utterances. However, similar effects have been reported in patients with lesions of the supplementary motor area (SMA) (Laplane et al., 1977; Ziegler et al., 1997; Krainik et al., 2003), a region of the premotor cortex that corresponds to BA 6 , in the dorsomedial region of the prefrontal cortex. The DMPFC investigated in the present report most probably corresponds to the agranular area $6 \mathrm{~m}$ (Burman et al., 2006). In squirrel monkeys, pharmacological blockade of the PAG by a glutamatergic antagonist prevented the vocal emission elicited by electrical stimulation of the ACC, but did not block vocalizations elicited by SMA stimulation (Jürgens and Zwirner, 1996). These results led the group to postulate the existence of two parallel vocal pathways, one involving the PAG and controlled by the ACC and another independent of the PAG and controlled by the SMA. According to this view, the former pathway would be responsible for the utterance of innate vocalizations related to the emotional state of the subject, while the latter pathway would trigger learned vocalizations (Jürgens, 2002).

If the ACC and the DMPFC are selectively involved in the voluntary initiation of vocal output, which area would be responsible for the control of the acoustic features of the vocalizations in the non-human primate brain? The debate on the possible existence of a homologue of Broca's area in the VLPFC of marmosets dates back to the first half of the last century (Brodmann, 1909; von Bonin and Peden, 1947). The latter authors considered the anterior portion of the area along the frontoparietal operculus of the marmoset brain to be a homologue of Broca's area. More recent work did not refer to any cytoarchitectonic areas that might represent a marmoset homologue of human or macaque BA 44 (Burman et al., 2006). Rather, it indicates that the ventrolateral area of the marmoset prefrontal cortex resembles cortical area 47/12 of the macaque brain (Petrides and Pandya, 2002), characterized by a sharply defined layer II and a well-developed layer IV, although not as thick as in adjacent areas 10 and 46. Still according to this study, the marmoset VLPFC is limited dorsally by a transitional region that resembles area 45 in the macaque and human brains, with a thick layer IV limited by large darkly Nissl-stained neurons in layers III and V (Burman et al., 2006). Since the ventrolateral region resembles both area $47 / 12$ in macaques and area 45 in macaques and humans, it was called area 12/45 in marmosets (Burman et al., 2006).

The injection of anterograde and retrograde tracers revealed that area $12 / 45$ is the most extensively connected among the prefrontal areas analyzed, which also comprised dorsal, orbital, medial, and lateral areas (Roberts et al., 2007). In macaques, both areas 47/12 and 45 receive polymodal afferents: While area $47 / 12$ receives robust inputs from associative visual areas in the rostral inferotemporal cortex, area 45 receives inputs from rostral auditory regions in the superior temporal cortex (Romanski et al., 1999; Petrides and Pandya, 2002). In the marmoset brain, it is not possible to make a clear distinction between areas 12 and 45, although some degree of specialization has been observed in projections to secondary visual areas (Burman et al., 2006; Roberts et al., 2007).

Our results show intense activation of the marmoset VLPFC as a whole during vocal production. Statistical analyses within individuals indicate that layer IV and its borders with layers III and V comprise the region with the highest number of labeled cells within the VLPFC (Figure 8A). Area 45 in the monkey brain has been suggested to play a specific role in the active - i.e. not automatic retrieval of mnemonic information, when the stimuli do not bear reliable relationships to other stimuli or to particular contexts, thus creating the need for some degree of judgment (Petrides, 1996). In humans, BA 45 is believed to take part in episodic memory retrieval (Cabeza et al., 2002), while BA 44 seems to integrate a subvocal rehearsal system for verbal working memory (Baddeley, 1992; Paulesu et al., 1993). However, the importance of the VLPFC for the evolution of speech and vocal control in primates is not restricted to its activation during vocal behavior. In addition to an involvement in the control of orofacial musculature (Petrides et al., 2005) and working memory, the VLPFC comprises motor area F5c, the site where mirror neurons were first discovered in macaques (Rizzolatti et al., 1996). This area has been considered by some authors as the macaque homologue of human area 44, and the mirror system has been suggested to integrate a core area for the motor learning of speech. Notwithstanding, area F5 is agranular (Rizzolatti et al., 1996), while area 44 is dysgranular (Amunts et al., 1999). Indeed a dysgranular area similar to area 44, just neighboring area F5, has been described in the monkey brain (Petrides et al., 2005). On the other hand, both area F5 in macaques and area 44 in humans have been reported to be responsive to both hand and mouth movements (Rizzolatti et al., 2002). Although the inclusion of area 44 in the mirror system is still debatable, the apparent superimposition of hand and mouth representations in human cortical areas involved with complex actions and necessary for speech control gives intriguing clues regarding the evolution of speech.

A comparative analysis of our marmoset data with data from areas $47 / 12$, 44, and 45 in macaques and 44 and 45 in humans suggests a progressive anatomical and functional specialization of the VLPFC areas towards the fine control of vocal expression in primates (Table 1), in a manner much similar to that proposed by (Rilling et al., 2008) for the evolution of the arcuate fasciculus. The involvement of these areas with vocal control in non-human primates suggests that their primordial vocal function greatly precedes human speech, and probably served as a pre-adaptation for the emergence of human speech. While the ACC seems to modulate volitional motor outputs by interfacing cognition and emotion, the VLPFC may have evolved as the site of spoken language in humans by interfacing crucial capabilities underlying speech, such as highlevel orofacial control, working memory, and the mirror system.

\section{CONCLUSION}

Our results support the notion that diverse cortical structures are involved in the control of vocal communication in marmosets. The cortical areas investigated here, previously reported to be associated with auditory processing and vocal control in humans and macaques, are also activated in the marmoset brain during hearing and vocal production. Most importantly, our data provide direct evidence that the VLPFC, a key region for speech control in humans, is also activated during vocal production in a non-human primate. The overall coherence of our results with the recent literature on vocal control in the human and macaque brains seems to push the debate on the evolution of speech back in the primate evolutionary branch, so as to include New World monkeys in the picture. 
Table 1 | Cytoarchitectonic and functional differences of the primate VLPFC across three primate species.

\begin{tabular}{|c|c|c|c|}
\hline & Callithrix jacchus & Macaca sp. & Homo sapiens \\
\hline Area 44 & Absent? & $\begin{array}{l}\text { Present. } \\
\text { - Control of orofacial musculature. }\end{array}$ & $\begin{array}{l}\text { Present. } \\
\text { - Speech control. }\end{array}$ \\
\hline
\end{tabular}

Marmoset data from (von Bonin and Peden, 1947; Burman et al., 2006; Roberts et al., 2007) and this study; macaque data from (Petrides, 1996; Rizzolatti et al., 1996; Romanski and Goldman-Rakic, 2002; Petrides et al., 2005); human data from (Baddeley, 1992; Paulesu et al., 1993; Amunts et al., 1999; Cabeza et al., 2002).

\section{REFERENCES}

Aitkin, L., and Park, V. (1993). Audition and the auditory pathway of a vocal new world primate, the common marmoset. Prog. Neurobiol. 41, 345-367. Available at:http://cat.inist.fr/?aModel $\mathrm{e}=$ afficheN\&cpsidt $=4821812$.

Aitkin, L. M., Kudo, M., and Irvine, D. R. (1988). Connections of the primary auditory cortex in the common marmoset, Callithrix jacchus jacchus. J. Comp. Neurol. 269, 235-248. Available at: http://www.ncbi.nlm.nih.gov/ pubmed/3128585.

Aitkin, L. M., Merzenich, M. M., Irvine, D. R., Clarey, J. C., and Nelson, J. E. (1986). Frequency representation in auditory cortex of the common marmoset (Callithrix jacchus jacchus). J. Comp. Neurol. 252, 175-185. Available at: http://www.ncbi.nlm.nih.gov/ pubmed/3782506.

Aitken, P. G. (1981). Cortical control of conditioned and spontaneous vocal behavior in rhesus monkeys. Brain Lang. 13, 171-184. Available at: http:// linkinghub.elsevier.com/retrieve/ pii/0093934X81901371.

Amunts, K., Schleicher, A., Bürgel, U., Mohlberg, H., Uylings, H. B., and Zilles, K. (1999). Broca’s region revisited: cytoarchitecture and intersubject variability. J. Comp. Neurol. 412, 319341. Available at: http://www.ncbi. nlm.nih.gov/pubmed/10441759.

An, X., Bandler, R., Ongür, D., and Price, J. L. (1998). Prefrontal cortical projections to longitudinal columns in the midbrain periaqueductal gray in macaque monkeys. J. Comp. Neurol. 401, 455-479. Available at: http://www.ncbi.nlm.nih.gov/ pubmed/9826273.

Arnold, K., and Zuberbühler, K. (2006). Language evolution: semantic combinations in primate calls. Nature 441 , 303. Available at: http://www.ncbi. nlm.nih.gov/pubmed/16710411.

Baddeley, A. (1992). Working memory. Science 255, 556-559. Available at: http://www.ncbi.nlm.nih.gov/ pubmed/1736359.

Barbas, H., Ghashghaei, H., Dombrowski, S. M., and Rempel-Clower, N. L. (1999). Medial prefrontal cortices are unified by common connections with superior temporal cortices and distinguished by input from memoryrelated areas in the rhesus monkey. J. Comp. Neurol.410,343-367. Available at: http://www.ncbi.nlm.nih.gov/ pubmed/10404405.

Bendor, D., and Wang, X. (2005). The neuronal representation of pitch in primate auditory cortex. Nature 436, 11611165. Available at: http://www.ncbi. nlm.nih.gov/pubmed/16121182.

Bendor, D., and Wang, X. (2007). Differential neural coding of acoustic flutter within primate auditory cortex. Nat. Neurosci. 10, 763-771. Available at: http://www.ncbi.nlm.nih.gov/ pubmed/17468752.

Boinski, S. (1993). Vocal coordination of troop movement among white-faced capuchin monkeys, Cebus capucinus. Am. J. Primatol. 30, 85-100. Available at: http://www3.interscience.wiley. com/journal/110512066/abstract.

Boinski, S., Moraes, E., Kleiman, D., and Dietz, J. (1994). Intra-group vocal behaviour in wild golden lion tamarins, Leontopithecus rosalia: honest communication of individual activity. Behaviour 130, 1-2. Available at: http://www.jstor.org/ stable/4535206.

Brodmann, K. (1909). Vergleichende Lokalisationslehre der Grosshirnrinde in ihren Prinzipien dargestellt auf.... Barth Leipzig. Available at: http://scholar.google.com.br/ scholar?hl $=$ pt-BR\&q $=$ brodm $\mathrm{ann}+\mathrm{k} \& \mathrm{btnG}=$ Pesquisar\&lr $=$ \&as_ylo $=\# 0$.

Burman, K. J., Palmer, S. M., Gamberini, M., and Rosa, M. G. (2006). Cytoarchitectonic subdivisions of the dorsolateral frontal cortex of the marmoset monkey (Callithrix jacchus), and their projections to dorsal visual areas. J. Comp. Neurol. 495, 149-172. Available at:http://www.ncbi.nlm.nih. gov/pubmed/16435289.

Cabeza, R., Dolcos, F., Graham, R., and Nyberg, L. (2002). Similarities and differences in the neural correlates of episodic memory retrieval and working memory. NeuroImage 16,317-330. Available at: http://www.ncbi.nlm.nih. gov/pubmed/12030819.

Chaudhuri, A. (1997). Neural activity mapping with inducible transcription factors. Neuroreport 8, 5-9. Available at: http://www.ncbi.nlm.nih.gov/ pubmed/9427298.

Clark, A., and Wrangham, R. (1994). Chimpanzee arrival pant-hoots: do they signify food or status? Int. J. Primatol. 15, 185-205. Available at: http://www.springerlink.com/ index/10.1007/BF02735273.

Council, N. R. (1996). Guide for the Care and Use of Laboratory Animals. Washington, DC: National Academies Press.Available at:http://www.amazon. com/Guide-Care-Use-LaboratoryAnimals/dp/0309053773.

de la Mothe, L. A., Blumell, S., Kajikawa, Y., and Hackett, T. A. (2006). Cortical connections of the auditory cortex in marmoset monkeys: core and medial belt regions. $J$. Comp. Neurol. 496, 27-71. Available at: http://www.ncbi.nlm.nih.gov/ pubmed/16528722.

Düsterhöft, F., Häusler, U., and Jürgens, U. (2000). On the search for the vocal pattern generator. A single-unit recording study. Neuroreport 11, 2031-2034. Available at:http://www.ncbi.nlm.nih. gov/pubmed/10884066.

Epple, G. (1968). Comparative studies on vocalization in marmoset monkeys (Hapalidae). Folia Primatol.; Int. J Primatol. 8, 1-40. Available at: http://www.ncbi.nlm.nih.gov/ pubmed/4966050

Ghazanfar, A., and Hauser, M. (1999). The neuroethology of primate vocal communication: substrates for the evolution of speech. Trends Cogn. Sci.3, 377-384. Available at:http://www.ncbi. nlm.nih.gov/pubmed/10498928.

Ghazanfar, A. A., Flombaum, J. I., Miller, C. T., and Hauser, M. D. (2001). The units of perception in the antiphonal calling behavior of cotton-top tamarins (Saguinus oedipus): playback experiments with long calls. J. Comp. Physiol. A, Sens., Neural Behav. Physiol. 187, 27-35. Available at: http://www.ncbi.nlm.nih.gov/ pubmed/11318375.

Ghazanfar, A. A., and Miller, C. T. (2006). Language evolution: loquacious monkey brains? Curr. Biol. CB 16, R879R881. Available at: http://www.ncbi. nlm.nih.gov/pubmed/17055970.

Gil-da-Costa, R., Martin, A., Lopes, M. A., Muñoz, M., Fritz, J. B., and Braun, A. R. (2006). Species-specific calls activate homologs of Broca's and Wernicke's areas in the macaque. Nat. Neurosci. 9, 1064-1070. Available at: http://www.ncbi.nlm.nih.gov/ pubmed/16862150.

Jarvis, E. D., and Mello, C. V. (2000). Molecular mapping of brain areas involved in parrot vocal communication. J. Comp. Neurol. 419, 1-31. Available at: http://www.ncbi.nlm. nih.gov/pubmed/10717637.

Jarvis, E. D., and Nottebohm, F. (1997). Motor-driven gene expression. Proc. Natl. Acad. Sci. 94, 4097-4102. Available at http://www.ncbi.nlm.nih. gov/pubmed/9108111.

Jarvis, E. D., Ribeiro, S., da Silva, M. L., Ventura, D., Vielliard, J., and Mello, C. V. (2000). Behaviourally driven gene expression reveals song nuclei in hummingbird brain. Nature 406, 628-632. Available at: http://www.ncbi.nlm.nih. gov/pubmed/10949303.

Jones, M. W., Errington, M. L., French, P. J., Fine, A., Bliss, T.V., Garel, S., Charnay, P., Bozon, B., Laroche, S., and Davis, S. (2001). A requirement for the immediate early gene Zif268 in the expression 
of late LTP and long-term memories. Nat. Neurosci. 4, 289-296. Available at: http://www.ncbi.nlm.nih.gov/ pubmed/11224546.

Jürgens, U. (2002). Neural pathways underlying vocal control. Neurosci. Biobehav. Rev. 26, 235-258. Available at: http://www.ncbi.nlm.nih.gov/ pubmed/11856561

Jürgens, U. (2009). The neural control of vocalization in mammals: a review. J. Voice 23, 1-10. Available at: http://www.ncbi.nlm.nih.gov/sites/ pubmed.

Jürgens, U., Lu, C. L., and Quondamatteo, F. (1996). C-fos expression during vocal mobbing in the new world monkey Saguinus fuscicollis. Eur. J. Neurosci. 8,2-10. Available at: http://www.ncbi. nlm.nih.gov/pubmed/8713445.

Jürgens, U., Maurus, M., Ploog, D., and Winter, P. (1967). Vocalization in the squirrel monkey (Saimiri sciureus) elicited by brain stimulation. Exp. Brain Res. 4, 114-117. Available at: http://www.springerlink.com/ index/10.1007/BF00240356.

Jürgens, U., and Ploog, D. (1970). Cerebral representation of vocalization in the squirrel monkey. Exp. Brain Res. 10, 532-554. Available at: http://www. springerlink.com/index/10.1007/ BF00234269.

Jürgens, U., and Pratt, R. (1979a). Role of the periaqueductal grey in vocal expression of emotion. Brain Res. 167, 367-378. Available at: http://www. ncbi.nlm.nih.gov/pubmed/109167.

Jürgens, U., and Pratt, R. (1979b). The cingular vocalization pathway in the squirrel monkey. Exp. Brain Res. Experimentelle Hirnforschung. Expérimentation cérébrale 34, 499510. Available at: http://www.ncbi. nlm.nih.gov/pubmed/105921.

Jürgens, U., and Zwirner, P. (1996). The role of the periaqueductal grey in limbic and neocortical vocal fold control. Neuroreport 7, 2921-2923. Available at: http://www.ncbi.nlm.nih.gov/ pubmed/9116210.

Kittelberger, J. M., Land, B. R., and Bass, A. H. (2006). Midbrain periaqueductal gray and vocal patterning in a teleost fish. J. Neurophysiol. 96, 71-85. Available at: http://www.ncbi.nlm.nih. gov/pubmed/16598068.

Knapska, E., and Kaczmarek, L. (2004). A gene for neuronal plasticity in the mammalian brain: Zif268/Egr-1/ NGFI-A/Krox-24/TIS8/ZENK? Prog. Neurobiol. 74, 183-211. Available at: http://www.ncbi.nlm.nih.gov/ pubmed/15556287.

Krainik, A., Lehéricy, S., Duffau, H., Capelle, L., Chainay, H., Cornu, P., Cohen, L., Boch, A., Mangin, J., Le Bihan, D., and Marsault, C. (2003). Postoperative speech disorder after medial frontal surgery: role of the supplementary motor area. Neurology 60 , 587-594.Available at: http://www.ncbi. nlm.nih.gov/pubmed/12601097.

Laplane, D., Talairach, J., Meininger, V., Bancaud, J., and Orgogozo, J. M. (1977). Clinical consequences of corticectomies involving the supplementary motor area in man. J. Neurol. Sci.34, 301-314. Available at: http://www.ncbi.nlm.nih. gov/pubmed/591992.

Lu, T., Liang, L., and Wang, X. (2001). Temporal and rate representations of time-varying signals in the auditory cortex of awake primates. Nat. Neurosci. 4, 1131-1138. Available at: http://www.ncbi.nlm.nih.gov/ pubmed/11593234.

Lüthe, L., Häusler, U., and Jürgens, U. (2000). Neuronal activity in the medulla oblongata during vocalization. A single-unit recording study in the squirrel monkey. Behav. Brain Res. 116, 197-210. Available at: http://www.ncbi.nlm.nih.gov/ pubmed/11080551.

Mello, C. V. (2002). Mapping vocal communication pathways in birds with inducible gene expression. J. Comp. Physiol. A Neuroethol. Sens. Neural Behav. Physiol. 188, 943-59. Available at http://www.ncbi.nlm.nih.gov/ pubmed/12471493.

Mello, C.V., and Ribeiro, S. (1998).ZENK protein regulation by song in the brain of songbirds. J. Comp. Neurol. 393, 426-438. Available at: http://www. ncbi.nlm.nih.gov/pubmed/9550149.

Mello, C. V., Vicario, D. S., and Clayton, D. F. (1992). Song presentation induces gene expression in the songbird forebrain. Proc. Natl. Acad. Sci. U.S.A. 89, 6818-6822. Available at: http://www. pubmedcentral.nih.gov/articlerender. fcgi ?artid $=49595 \&$ tool $=$ pmcentrez \&rendertype $=$ abstract.

Mendes, S. L., Vielliard, J., and De Marco, Jr. P. (2009). "The vocal identity of the Callithrix species," in The Smallest Anthropoids: The Marmoset/ Callimico Radiation Developments in Primatology: Progress and Prospects, eds S. M. Ford, L. M. Porter, and L. C. Davis (Berlin: Springer) 63-84. Available at: http://www.amazon.com/ Smallest-Anthropoids-CallimicoDevelopments-Primatology/ dp/1441902929.

Miller, C. T., Ashley, P., Hendry, S., and Wang, X. (2005). The functional neuroanatomy of a natural primate vocal behavior: antiphonal calling in common marmosets. Neuroscience Meeting Planner. Washington, DC: Society for Neuroscience.

Miller, C. T., and Wang, X. (2006). Sensory-motor interactions modulate a primate vocal behavior: antiphonal calling in common marmosets. J.
Comp. Physiol. A, Neuroethol. Sens., Neural Behav. Physiol. 192, 27-38. Available at: http://www.ncbi.nlm. nih.gov/pubmed/16133500.

Müller-Preuss, P., Newman, J. D., and Jürgens, U. (1980). Anatomical and physiological evidence for a relationship between the 'cingular' vocalization area and the auditory cortex in the squirrel monkey. Brain Res. 202, 307-315. Available at: http://www. ncbi.nlm.nih.gov/pubmed/7437905.

Nagarajan, S. S., Cheung, S. W. Bedenbaugh, P., Beitel, R. E., Schreiner, C. E., and Merzenich, M. M. (2002). Representation of spectral and temporal envelope of twitter vocalizations in common marmoset primary auditory cortex. J. Neurophysiol. 87, 1723-1737. Available at: http://www.ncbi.nlm.nih. gov/pubmed/11929894.

Paulesu, E., Frith, C. D., and Frackowiak, R. S. (1993). The neural correlates of the verbal component of working memory. Nature 362, 342-345. Available at: http://www.ncbi.nlm. nih.gov/pubmed/8455719.

Paus, T. (2001). Primate anterior cingulate cortex: where motor control, drive and cognition interface. Nat. Rev. Neurosci. 2, 417-424. Available at: http://www.ncbi.nlm.nih.gov/ pubmed/11389475.

Petkov, C. .I., Kayser, C., Steudel, T. Whittingstall, K., Augath, M., and Logothetis, N. K. (2008). A voice region in the monkey brain. Nat. Neurosci. 11, 367-374. Available at: http://www.ncbi.nlm.nih.gov/ pubmed/18264095.

Petrides, M., Cadoret, G., and Mackey, S. (2005). Orofacial somatomotor responses in the macaque monkey homologue of Broca's area. Nature 435, 1235-1238. Available at: http://www.ncbi.nlm.nih.gov/ pubmed/15988526.

Petrides, M., and Pandya, D. N. (2002) Comparative cytoarchitectonic analysis of the human and the macaque ventrolateral prefrontal cortex and corticocortical connection patterns in the monkey. Eur. J. Neurosci. 16, 291310. Available at: http://www.ncbi. nlm.nih.gov/pubmed/12169111.

Petrides, M. (1996). Specialized systems for the processing of mnemonic information within the primate frontal cortex. Phil. Trans. Roy. Soc. London. B, Biol. Sci. 351, 1455-1461; discussion 1461-1462. Available at: http://www.ncbi.nlm.nih.gov/ pubmed/8941957.

Rauschecker, J. P., Tian, B., and Hauser, M. (1995). Processing of complex sounds in the macaque nonprimary auditory cortex. Science 268, 111-114. Available at: http://www.ncbi.nlm.nih. gov/pubmed/7701330.
Ribeiro, S., Cecchi, G. A., Magnasco, M. O., and Mello, C. V. (1998). Toward a song code: evidence for a syllabic representation in the canary brain. Neuron 21, 359-371. Available at: http://www.ncbi.nlm.nih.gov/ pubmed/9728917.

Rilling, J. K., Glasser, M. F., Preuss, T. M. Ma, X., Zhao, T., Hu, X., and Behrens, T.E. (2008). The evolution of the arcuate fasciculus revealed with comparative DTI. Nat. Neurosci. 11, 426-428. Available at: http://www.ncbi.nlm.nih. gov/pubmed/18344993.

Rizzolatti, G., Fadiga, L., Gallese, V., and Fogassi, L. (1996). Premotor cortex and the recognition of motor actions. Cogn. Brain Res. 3, 131-141. Available at: http://linkinghub.elsevier.com/ retrieve/pii/0926641095000380.

Rizzolatti, G., Fogassi, L., and Gallese, V. (2002). Motor and cognitive functions of the ventral premotor cortex. Curr. Opin. Neurobiol. 12, 149-154. Available at: http://linkinghub.elsevier.com/retrieve/pii/ S0959438802003082.

Roberts, A. C., Tomic, D. L., Parkinson, C. H., Roeling, T. A., Cutter, D. J., Robbins, T. W., and Everitt, B. J. (2007). Forebrain connectivity of the prefrontal cortex in the marmoset monkey (Callithrix jacchus): an anterograde and retrograde tracttracing study. J. Comp. Neurol. 502, 86-112. Available at: http://dx.doi. org/10.1002/cne.21300.

Romanski, L. M., and Goldman-Rakic, P. S. (2002). An auditory domain in primate prefrontal cortex. Nat. Neurosci. 5,15-16. Available at: http://www.ncbi. nlm.nih.gov/pubmed/11753413.

Romanski, L. M., Tian, B., Fritz, J., Mishkin, M., Goldman-Rakic, P. S. and Rauschecker, J. P. (1999). Dual streams of auditory afferents target multiple domains in the primate prefrontal cortex. Nat. Neurosci. 2, 11311136. Available at: http://www.ncbi. nlm.nih.gov/pubmed/10570492.

Seyfarth, R. M., Cheney, D. L., and Marler, P. (1980). Monkey responses to three different alarm calls: evidence of predator classification and semantic communication. Science 210, 801-803. Available at: http://www.ncbi.nlm.nih. gov/pubmed/7433999.

Siebert, S., and Jürgens, U. (2003). Vocalization after periaqueductal grey inactivation with the GABA agonist muscimol in the squirrel monkey. Neurosci. Lett. 340, 111-114. Available at: http://www.ncbi.nlm.nih. gov/pubmed/12668249.

Simões, C., Vianney, P., Marcondesde-Moura, M., Freire, M., Mello, L., Sameshima, K., Araújo, J., Nicolelis, M., Mello, C., and Ribeiro, S. (2007). Immediate-early gene 
expression induced by spontaneous vocalizations in the common marmoset (Callithrix jacchus) XXII FeSBE Annual Meeting. Águas de Lindóia/SP: Federação de Sociedades de Biologia Experimental.

Simões, C. S., Vianney, P. V., Moura, M. M., Freire, M., Mello, L. E., Sameshima, K., Araujo, J. F., Nicolelis, M., Mello, C. V., and Ribeiro, S. (2008). Egr-1 expression induced by spontaneous vocalizations in the ventrolateral prefrontal cortex of the common marmoset (Callithrix jacchus) I Congresso Ibro/Larc de Neurociências da América Latina Caribe e Península Ibérica. Búzios/RJ: Sociedade Brasileira de Neurociências e Comportamento.

Stephan, H., Baron, G., Schwerdtfeger, W. K. (1980). The Brain of the Common Marmoset: A Stereotaxic Atlas. Berlin, Heidelberg, New York: SpringerVerlag.

Stephan, C., and Zuberbühler, K. (2008). Predation increases acoustic complexity in primate alarm calls. Biol. Lett. 4, 641-644. Available at: http://www.ncbi. nlm.nih.gov/pubmed/18818146.

Sutton, D., Larson, C., and Lindeman, R. (1974). Neocortical and limbic lesion effects on primate phonation. Brain Res. 71, 61-75. Available at: http:// linkinghub.elsevier.com/retrieve/ pii/0006899374901917.
Vitale, A., Zanzoni, M., Queyras, A., and Chiarotti, F. (2003). Degree of social contact affects the emission of food calls in the common marmoset (Callithrix jacchus). Am. J. Primatol. 59, 21-28. Available at: http://www3.interscience.wiley.com/ journal/102523879/abstract.

von Bonin, G., and Peden, J. K. (1947). The neocortex of hapale. J. Comp. Neurol. 86, 37-63. Available at: http://doi. wiley.com/10.1002/cne.900860103.

Wang, X., and Kadia, S. (2001). Differential representation of speciesspecific primate vocalizations in the auditory cortices of marmoset and cat. J. Neurophysiol. 86, 2616-2620. Available at: http://jn.physiology.org/ cgi/content/abstract/86/5/2616.

Wang, X., Lu, T., Snider, R. K., and Liang, L. (2005). Sustained firing in auditory cortex evoked by preferred stimuli. Nature 435, 341-346. Available at: http://www.ncbi.nlm.nih.gov/ pubmed/15902257.

Wang, X., Merzenich, M. M., Beitel, R., and Schreiner, C.E. (1995). Representation of a species-specific vocalization in the primary auditory cortex of the common marmoset: temporal and spectral characteristics. J. Neurophysiol. 74, 2685-2706. Available at: http://www. ncbi.nlm.nih.gov/pubmed/8747224.

Winter, M. (1978). "Some aspects of the ontogeny of vocalizations of hand-reared common marmosets," in Hearn Biology and behaviour of marmosets: Proceedings of the Marmose Workshop Gottingen: H. Rothe, eds H. Rothe and H. J. Wolters (Gottingen, West Germany: Eigenverlag Hartmut. Rothe), 127-139. Available at: http://www.amazon.com/Biologybehaviour-marmosets-ProceedingsGottingen/dp/3980020207.

Wisden, W., Errington, M. L., Williams, S., Dunnett, S. B., Waters, C. Hitchcock, D., Evan, G., Bliss, T. V., and Hunt, S. P. (1990). Differential expression of immediate early genes in the hippocampus and spinal cord. Neuron 4, 603-614. Available at: http://www.ncbi.nlm.nih.gov/ pubmed/2108708.

Yamamoto, M.E., Arruda, M. D., Alencar, A. I., Sousa, M. B., and Araújo, A. (2009). "Mating systems and femalefemale competition in the common Marmoset, Callithrix jacchus," in The Smallest Anthropoids: The Marmoset/ Callimico Radiation (Developments in Primatology: Progress and Prospects), eds S. M. Ford, L. M. Porter, and L. C. Davis (Berlin: Springer), 119-134. Available at: http://www.amazon.com/ Smallest-Anthropoids-CallimicoDevelopments-Primatology/ $\mathrm{dp} / 1441902929$.

Ziegler, W., Kilian, B., and Deger, K. (1997). The role of the left mesial frontal cor- tex in fluent speech: evidence from a case of left supplementary motor area hemorrhage. Neuropsychologia 35, 1197-1208. Available at: http:// linkinghub.elsevier.com/retrieve/pii/ S0028393297000407.

Conflict of Interest Statement: The authors declare that the research was conducted in the absence of any commercial or financial relationships that could be construed as a potential conflict of interest.

Received: 13 August 2010; paper pending published: 31 August 2010; accepted: 06 September 2010; published online: 23 September 2010.

Citation: Simões CS, Vianney PVR, de Moura MM, Freire MAM, Mello LE, Sameshima K, Araújo JF, Nicolelis MAL, Mello CV and Ribeiro S (2010) Activation of frontal neocortical areas by vocal production in marmosets. Front. Integr. Neurosci. 4:123 doi:10.3389/ fnint.2010.00123

Copyright (C) 2010 Simões, Vianney, de Moura, Freire, Mello, Sameshima, Araújo, Nicolelis, Mello and Ribeiro. This is an open-access article subject to an exclusive license agreement between the authors and the Frontiers Research Foundation, which permits unrestricted use, distribution, and reproduction in any medium, provided the original authors and source are credited. 